\title{
The use of surrogates in implementation of the federal Endangered Species Act-proposed fixes to a proposed rule
}

\author{
Dennis D. Murphy • Paul S. Weiland
}

Published online: 6 March 2014

(C) The Author(s) 2014. This article is published with open access at Springerlink.com

\begin{abstract}
The US Fish and Wildlife Service and National Marine Fisheries Service recently proposed to amend existing regulations that implement the Endangered Species Act's interagency consultation process by codifying their preexisting practice of using surrogates to express the amount or extent of incidental take of listed species. The agencies contend that amendments both are necessary as a practical matter and are defensible on ecological grounds. They propose the use of surrogates, either in the form of a substitute species filling in for a species that is challenging to observe or measure, or a land-cover type or another habitat attribute, as proxies for the amount or extent of anticipated take. We contend that the proposed rule leaves the process of surrogate selection and application without essential implementation details and describe five essential steps in surrogate selection and validation. In sum, an obligatory validation procedure should clearly articulate the reasoning behind the selection of the surrogate, including describing the similarities in responses by the surrogate and target species to the same environmental phenomena, linking demographic responses to habitat extent and condition, and describing the uncertainties that accompany the relationship between the status and trends of the surrogate and those of the target species or its habitat under common circumstances.
\end{abstract}

\section{Introduction}

Many organisms that are conferred protection under the federal Endangered Species Act (ESA) are preternaturally

D. D. Murphy

Biology Department, University of Nevada, Reno, NV 89557, USA

P. S. Weiland $(\square)$

Nossaman LLP, 18101 Von Karman Avenue, Suite 1800, Irvine, CA 92612, USA

e-mail: pweiland@nossaman.com resistant to the assessment of their status and trends. Listed species, with some exceptions, tend to be scarce and infrequently encountered, and often vex conservation planners because they are elusive, may have cryptic behaviors, and accordingly manifest hidden or obscured ecological interactions within the environments that support them. Those species, about which we need information so that they can be afforded protection, are often those most challenging to engage - among many reasons, simply because they are rare (see Rabinowitz 1981; Gaston 1994).

The US Fish and Wildlife Service (FWS) and National Marine Fisheries Service (NMFS), the federal wildlife agencies with the responsibility to conserve imperiled species and the ecosystems upon which they depend (see ESA 1973, as amended), often account for the many infrequently observed species under their statutory charge by exercising a logical default; they draw inferences from taxonomically related or ecologically relevant species, from experiences with other species in similar environmental circumstances elsewhere, or from perceived salient attributes of the targeted species' habitats. In this context, the agencies recently proposed to amend the existing regulations that implement the interagency consultation process set out in Section 7 of the ESA by codifying their pre-existing practice of using surrogates to express the amount or extent of incidental take of listed species (FWS and NMFS 2013). ${ }^{1}$ The agencies contend that amendments both are necessary as a practical matter and defensible on ecological grounds.

\footnotetext{
${ }^{1}$ Federal agencies may develop and amend regulations intended to interpret and implement laws enacted by Congress and the President through notice-and-comment rulemaking procedures described in the Administrative Procedure Act. The rule proposed by FWS and NMFS would amend the existing set of regulations that implement Section 7 of the ESA. The proposed rule was published in the Federal Register in September 2013, and the comment period regarding the rule was closed in November 2013.
} 
The wildlife agencies commonly use surrogates or proxies to deduce salient ecological attributes of hard-to-assess federally listed animals and plants, and to inform the determinations and decisions made in exercising their authorities under the ESA - employing an ad hoc array of substitute species, surrogate measures, and environmental indicators (see Caro 2010). Inferences drawn from co-occurring, more-readily observed and better-studied species can be central to implementation of the ESA. To inform conservation of imperiled species, the agencies often draw guidance from more-readily available information on more-common species. To assess the extent and condition of the complex habitats that support many of those species, the wildlife agencies frequently rely on the area of a vegetation community for terrestrial species or simply defer to the body of water in which an aquatic species resides.

The use of surrogates, either in the form of a substitute species filling in for a species that is challenging to observe or measure, or a land-cover type or other habitat attribute as a proxy for a species' habitat or its distribution, is not just an efficiency; inferences drawn from surrogates can be a necessity. For many species - certainly those so elusive that detection can be an insurmountable challenge - a census by survey may not be practicable, and conjecture from experiences with similar species can serve as means of evaluating the status of a listed species, determining its trends in abundance, and setting quantitative thresholds for management actions, including establishing take limits. Absent surrogates and proxy measures, in a substantial number of cases, it is not clear that the wildlife agencies could effectively exercise their statutory authorities.

\section{Description of the proposed rule}

The wildlife agencies propose to amend existing regulations to clarify that surrogates can be used to express the amount or extent of anticipated take in incidental take statements issued under Section 7(b)(4) of the ESA (1973), as amended. ${ }^{2}$ Specifically, the proposed rule states: "A surrogate (e.g., habitat or ecological conditions or similarly affected species) may be used to express the amount or extent of anticipated take provided that the incidental take statement describes the causal link between effects to the surrogate and take of the listed species, why it is not practical to express the amount or extent of anticipated take or to monitor take-related impacts in terms of individuals of the listed species, and sets a clear standard for determining when the level of anticipated take has been exceeded" (FWS and NMFS 2013, p.54442). The preamble

\footnotetext{
${ }^{2}$ The term "take" is defined in the ESA as "harass, harm, pursue, hunt, shoot, wound, kill, trap, capture, or collect, or to attempt to engage in any such conduct."
}

of the rule explains the need for a surrogate option- - "Such flexibility may be especially useful in cases where the biology of the listed species or the nature of the proposed action makes it impractical to detect or monitor take-related impacts individual animals" (FWS and NMFS 2013, p.54439).

In proposing the use of surrogates to inform certain agency determinations, instead of carrying out direct assessment of impacts on listed species, the wildlife agencies acknowledge that Congress (in conference, H.R. Rep. no. 97-567 at 27) prefers that agency determinations express "impacts of take in incidental take statements in terms of a numerical limitation with respect to individuals of the listed species" (FWS and NMFS 2013, pp.54437-54438). At the same time, the agencies go on to assert that Congress "recognized that a numerical value would not always be available and intended that such numbers only be established where possible" (FWS and NMFS 2013, p.54438). Referencing the preamble to the final rule codified in the existing regulations, the wildlife agencies suggest that addressing take in terms of the extent of impacts to habitat, in contrast to numerical losses of individuals of a listed species, may be more appropriate "because for some species loss of habitat resulting in death and injury to individuals may be more deleterious than the direct loss of a certain number of individuals" (FWS and NMFS 2013, p.54438).

\section{History of surrogates in conservation biology}

The proposed rule is not formal recognition of much needed latitude in implementing the ESA; it is actually codification of a long-exercised policy. Inferences drawn from co-occurring, more-readily observed, and better-studied species, ecological communities, and environmental attributes form the basis for much of the knowledge that has been gleaned regarding atrisk species. And, surrogates, as often as not, manifest as reasonable shortcuts in agency determinations. The status of microscopic fairy shrimp in southern California's vanishing vernal pool complexes, which survive as nearly invisible cysts in the soil through dry seasons and episodic droughts, is inferred by FWS from the extent and numbers of the ponds and pools that they occupy. So very few pallid sturgeon (Scaphirhynchus albus) ply the upper Missouri River that FWS is forced to draw some of its conclusions regarding the species' ecology from the much more abundant, co-occurring shovelnose sturgeon. Some specialists who study the valley elderberry longhorn beetle (Desmocerus californicus dimorphus) have never seen the brightly colored adults that appear briefly each year in riparian forests in California's Central Valley; FWS documents its local presence and infers its status forensically from exit holes left in elderberry stems after its larvae complete metamorphosis in their host plants.

Even for less-elusive and more frequently encountered species, it is de rigueur for wildlife biologists to infer status 
and trends and the extent and quality of the habitats of those species using proxy measures - drawing conclusions regarding habitat conditions for songbirds by mapping the area of particular vegetation communities, using forest-stand age and structure to assume carrying capacity for species that inhabit late-seral and old-growth forests, and assessing the status of spawning areas for salmon by counting gravel bars and stream riffles. Predictably, even the fundamental act of assessing the size and distribution of a listed species generally uses inferences-assuming population sizes from geographic or temporal subsamples, and inferring species' geographic range limits and gaps from reasonable surveys across environmental gradients.

The exercise of conservation planning in California's Sacramento-San Joaquin Delta serves as an archetype backdrop for both the use of surrogates and the need for robust validation thereof. In the Delta, a host of agencies involved in operations of water management facilities coordinate with FWS and NMFS to develop a conservation agenda for atrisk fishes in turbid estuarine waters that make direct observation impossible, monitoring of aquatic species an inferential challenge, and characterization and assessment of habitat extent and condition challenging. The endemic delta smelt (Hypomesus transpacificus) has proven exceptionally difficult to assess for purposes of conservation planning - even a rough estimate of its population size is not available, and the existing rule designating critical habitat for the species is 20 years old and fails to identify the geographic areas essential to the conservation of the species with specificity, as the ESA requires. ${ }^{3}$ Absent direct measure of either delta smelt population numbers or the extent and condition of its habitat, FWS has defaulted to using numbers of delta smelt salvaged at water export pumps as a surrogate measure of delta smelt individuals lost to entrainment in the south Delta (see Kimmerer 2008). Furthermore, FWS has used the position of the low-salinity zone in the Delta, which is affected predominantly by river flows and tides, as a surrogate measure for the extent and quality of habitat available for delta smelt (FWS 2008 citing Feyrer et al. 2007; Feyrer et al. 2008), and others have used it as a surrogate for the location of the delta smelt population (Rose et al. 2013a, b). A regional demographic unit of longfin smelt (Spirinchus thaleichthys), a species found along the Pacific Coast from Alaska to southern California, was found to warrant listing by FWS from open

\footnotetext{
${ }^{3}$ Critical habitat is defined in the ESA as "(i) the specific areas within the geographical area occupied by the species, at the time it is listed in accordance with the provisions of Section 4 of this Act, on which are found those physical or biological features (I) essential to the conservation of the species and (II) which may require special management considerations or protection; and (ii) specific areas outside the geographical area occupied by the species, at the time it is listed in accordance with the provisions of Section 4 of this Act, upon a determination by the Secretary that such areas are essential for the conservation of the species."
}

water surveys in the San Francisco estuary (FWS 2012). Longfin smelt numbers derived from those surveys, which are assumed to provide a surrogate measure of the status and trends in overall numbers of the fish in the estuary, are correlated with outflow through the Delta during spring months (Rosenfield and Baxter 2007). However, water export policy is being determined based on this correlation, even though the surveys cover only a fraction of the area of the San Francisco estuary utilized by the fish. A biological opinion issued in 2009 by NMFS included species-specific conservation management actions for the Sacramento River winter-run Chinook salmon (Oncorhynchus tshawytscha), Central Valley springrun Chinook salmon, Central Valley steelhead (Oncorhynchus mykiss), and the southern distinct population segment of the North American green sturgeon (Acipenser medirostris), in part drawing inferences regarding those fishes' responses to environmental stressors and survival rates from a single surrogate - the much more numerous hatchery-reared fall-run Chinook salmon that ply the same Delta water courses (National Marine Fisheries Service 2009). Even a cursory appraisal of the ecological and behavioral attributes of hatchery-reared Chinook should lead resource managers to reject it as a surrogate for wild steelhead and green sturgeon, which have substantially different life histories (Murphy et al. 2011). In each of the cases in which surrogates have been used to draw inferences regarding the status or trends of at-risk fishes in the Delta, the responsible agencies have done so without validating the surrogate-target species relationship.

Ecological theory challenges the very legitimacy of using information from surrogates to guide conservation management of other species. No two species, it is contended, can occupy the same ecological niche for long (Hardin 1960; Hutchinson 1961). And, where seemingly similar species do co-exist, they must differ in one or more characteristics that affect the fitness of each. That considered, it would be unwise to assume that differences between similar and co-occurring species would not extend to their responses to the environmental stressors that may put the target species at risk.

Even more to the point, a quarter of a century of focused scientific literature now constitutes a substantial body of scholarship pertaining to the use of surrogates in conservation planning. Numerous case studies investigating the distributions and abundances of co-occurring species have found few examples wherein information from one species would be effective in determining conservation responses of one or more others (Dickson et al. 2009; Fleishman and Murphy 2009: Banks et al. 2010); those studies include a diversity of animal and plant groups (see, for example, Austin et al. 1990; Launer and Murphy 1994; Rowland et al. 2006). Conservation biologists, recognizing that wildlife and land management agencies are constrained by resources and challenged by the logistics of assessing multiple management targets, have used retrospective data sets to explore the effectiveness and efficacy 
of using readily available data on certain species to inform agency determinations and actions targeting other species for which data are lacking (see, for example, Landres 1992; Cushman and McKelvey 2009).

Scholars have raised doubts regarding whether the assumption that information could be derived from surrogate species and measures, and used to substitute for information from a species that is actually targeted for conservation action, is able to hold up in practice (see, for example, Caro 2010). Murphy et al. (2011) warn that the "surrogate species concept does not have universal application and must be applied prudently" and note that the parsimonious conclusion from more than two decades of direct and retrospective studies is that at best weak concordance can be expected between the demographic responses of surrogates and listed species that are targeted by management actions. Landres et al. (1988) explored the premise that "an organism that responds to relevant environmental conditions in a manner similar to a target species, for which data are too difficult, inconvenient, or expensive to gather" could have reliable application in the US Forest Service's "management indicator species" approach to land use planning, and concluded that the use of surrogates "fails on conceptual and empirical grounds." Lambeck (1997) warned that critical assessment of available data must be undertaken to ascertain whether the use of surrogates is necessary, justified, or logistically possible. Caro and O'Doherty (1999) offer that objective criteria from which surrogates are chosen need to be explicitly specified, and Lindenmayer et al. (2002) observe that a surrogate-based approach to conservation planning is "data intensive and demands detailed information."

For these reasons, the proposition that surrogates should be used only when it is not feasible to use data regarding a target species, and then only after ascertaining whether the surrogate and the target species are highly likely to respond in essentially the same manner to particular environmental conditions, has been broadly accepted in the standing scientific literature. Unfortunately, the proposed rule references not a single article, book chapter, or book on the subject of surrogates, although dozens - including those cited above-have been published in the last few decades (FWS and NMFS 2013). Moreover, the proposed rule does not take adequate account of the clear lessons that have emerged from that scientific literature.

\section{Judicial perspectives on the use of surrogates}

The proposed rule is presented as an institutional response to court decisions "regarding the adequacy of incidental take statements...to clarify...the use of surrogates such as habitat, ecological conditions or similar affected species, to express the amount or extent of anticipated incidental take, including circumstances where project impacts to the surrogate are coextensive with at least one aspect of the project's scope", rather than as a response to scientific developments (FWS and NMFS 2013, p.54437). The notice calls out decisions in seven recent court cases that challenged agency determinations under Section 7 of the ESA as compelling the wildlife agencies to establish prospective standards regarding incidental take statements. The judiciary struck as arbitrary the use of surrogates in six of the seven cases. In light of the wildlife agencies' poor track record in court, the proposed rule may be interpreted as an effort by the agencies to tip the balance in their favor in future cases.

The proposed rule references caselaw that generally reflects judicial skepticism of the wildlife agencies' past practices. The courts universally recognize that the legislative history of the ESA provides evidence that Congress wanted the wildlife agencies to express take in quantitative terms. Nonetheless, a number of decisions have expressly held that a surrogate-rather than a numerical limit expressed in the form of take of a specified number of individuals of a listed species - is permissible if the latter cannot be practically obtained (Oregon Natural Resources Council v. Allen 2007, p.1038; Arizona Cattle Growers Assoc. v. U.S. Fish and Wildlife Service 2001, p.1250). But, courts have invalidated incidental take statements where the relevant wildlife agency failed to demonstrate that it is impractical to express a take limit in terms of the number of individuals of the species that can be taken. For example, in Miccosukee Tribe of Indians of Florida v. U.S. (2009), the Eleventh Circuit held that the use of habitat impact measurements in lieu of specific population data to assess incidental take of the endangered Cape Sable Seaside Sparrow (Ammodramus maritimus mirabilis) and other species was unlawful, because numerical population counts should be used where possible.

Where an agency has made the threshold showing described above, that agency may use a surrogate, but identification and selection of the surrogate cannot be arbitrary or capricious (Miccosukee Tribe of Indians of Florida v. U.S. 2009, p.1275). For example, in Miccosukee Tribe of Indians of Florida, use of a water-level drop at a single monitoring gauge during certain months of the year as a habitat-based surrogate for take of the endangered Everglade snail kite (Rostrhamus sociabilis plumbeus) violates the Administrative Procedure Act (APA). Furthermore, the wildlife agency must establish a causal connection between the response of the surrogate and take of the listed species (Arizona Cattle Growers Assoc. v. U.S. Fish and Wildlife Service 2001, p.1250; Center for Biological Diversity v. Bureau of Land Management 2006, p.1139). Thus, in Arizona Cattle Growers Assoc., where FWS used numerous ecological conditions collectively as a proxy for incidental take of the endangered loach minnow (Tiaroga cobitis), but did not discuss or otherwise establish a causal connection between the two, the Court of Appeals held that use of the proxy was arbitrary and capricious. 
A surrogate that exhibits an ecological response to an action that is too vaguely associated with that of the listed species de facto violates the APA because "it cannot accurately measure the level of allowable take" (Center for Biological Diversity v. National Marine Fisheries Service 2013, p.103; see also Center for Biological Diversity v. Bureau of Land Management 2006, p.1140). For example, using vegetative litter, native species diversity, channel structure, and water temperature as proxies for take of a listed species is unlawful, unless the wildlife agency has documented a connection between changes in those environmental attributes and the population response of a listed species (Arizona Cattle Growers Assoc. v. U.S. Fish and Wildlife Service 2001, p.1249). Likewise, a federal district court determined FWS acted unlawfully by simply counting acres of available habitat as a proxy for the census number of the threatened desert tortoise (Gopherus agassizii) (Center for Biological Diversity v. Bureau of Land Management 2006, p.1139). In sum, when using ecological conditions as a surrogate, the wildlife agency must establish a link between those conditions and the taking.

Caselaw sets minimum criteria for the use of surrogates that are wholly consistent with the standing body of scientific work on the subject described above. We contend it is incumbent on the wildlife agencies to embrace explicitly and build upon those criteria.

\section{The need to validate surrogates}

Required by statute and regulations to base determinations made under the Endangered Species Act on the "best available scientific and commercial data," it would seem that the agencies should consider the body of information generated by conservation biologists and applicable case law. Both demand that the proposed rule must be modified to incorporate a formal structured approach to surrogate selection. The lone criterion for surrogate selection that can be drawn from the proposed rule - the agencies must describe "the causal link between effects to the surrogate and take of the listed species"-is unacceptably spare. To be consistent with the "best available science" directive in the ESA, the wildlife agencies need to not only establish a "causal link" between the responses of the surrogate and those of the targeted resource, but also justify the use of the surrogate and articulate a validation procedure.

Cushman et al. (2010) used community-scale information on birds to conclude that using demographic information on one species to infer the abundances of others was unreliable. They found that efficacy of surrogates in predicting the distribution and abundance of others to be highly (geographically) scale dependent and found low power to detect demographic change in a target or indicator species from other species. The authors, as others before them, opine that in practice, the assumptions supporting surrogate selection need to be made explicit, presented as testable hypotheses, and confronted with available data - an obligatory process that Wenger (2008) suggests provides "a rational basis for instituting management policy even in the face of considerable uncertainty."

Caro et al. (2005) identify four steps to testing the assumption that one species can serve effectively to represent another for purposes of guiding management actions. They state that "if one absolutely cannot study the target species" one should: (a) identify the traits of the target species that are likely to affect its demographic viability and use that understanding to identify candidate surrogates that share those traits, (b) measure demographic vital rates for the candidate surrogates and relate them to effects of environmental disturbance to establish how stressors affect population viability, (c) consider surrogates with sufficiently broad ranges of trait values allowing for the relationship between trait values and stressors to be established, and (d) if that exercise cannot be carried out, attempt to relate at least one trait variable in the candidate surrogate that might predict the surrogate's ability to provide insights into how the target species would respond to similar environmental circumstances.

Instead of setting a "clear standard," by drawing upon the standing scientific literature, including Caro et al. (2005) and Wenger (2008), the proposed rule leaves the process of surrogate selection and application without essential implementation details. Nonetheless, we concur with the wildlife agencies that it is both necessary and appropriate to promulgate a rule that sets out the requisite steps in surrogate selection and validation. We contend that those steps must be informed by the best available scientific information reflected in the principles set out below. Using a surrogate to assess numerical take, FWS and NMFS should:

1. Provide an explanation of the reasons why the direct assessment in the form of take of a specified number of individuals of a listed species or a proportion of the population of that species cannot be measured and assessed. The justification for surrogate use should explicitly differentiate between ecological characteristics of the listed species or its habitat that impede data collection making rigorous assessment not possible, and any logistical and practical challenges that present impediments to or inconveniences in surveys or sampling efforts.

2. Apply a structured deductive process to match a prospective surrogate with the listed species, employing available demographic and geographic information, inferences from other species, and experiences from conservation planning efforts elsewhere, which have successfully or unsuccessfully engaged surrogate approaches.

3. Present a clear description of similarities and differences between the likely responses of the surrogate and target species to salient environmental phenomena, and identify 
any uncertainties that may manifest as different responses to environmental stressors. This is the point at which the causal nexus between the surrogate and target is acknowledged and critically examined. It may frequently be necessary to describe how data regarding the surrogate must be adjusted or corrected in order to allow for its use in the context of an incidental take statement.

4. Articulate a means by which post-determination implementation and monitoring will be designed, using adaptive management to explore continuously the relationship and ecological relatedness between the surrogate and the listed species, and the responses of both to environmental stressors. This is particularly critical in light of the fact that the extent to which biological opinions include monitoring and adaptive management varies considerably (Government Accountability Office 2009), and the observation by one court that any surrogate or other means employed to monitor impacts of incidental take is useful only insofar as that surrogate may be measured, and the requirement to monitor and report findings is specified concomitant with the take limit.

5. Provide assurance that reinitiation of consultation ${ }^{4}$ will occur if it is found that the surrogate does not adequately (accurately) reflect the salient ecological responses of the listed species at any point that the incidental take statement remains in effect.

To the extent practicable, the wildlife agencies should specify the amount or extent of incidental take of a target species without reliance on a surrogate. Where a surrogate is necessary, a validation procedure must be employed, which allows the wildlife agencies to use available demographic and other relevant data to establish a quantitative relationship between the chosen surrogate and take of the target species. In addition, the procedure should describe how data regarding the surrogate must be transformed to allow for its use in determining the incidental take level.

\section{Conclusion}

To the extent that the wildlife agencies intend to move ahead with codification of a rule to allow the use of a surrogate for take of listed species, they are obliged to assure the surrogate can reliably perform that function. A validation procedure should clearly articulate the reasoning behind the selection of the surrogate. It should explicitly describe the similarities in ecological responses by the surrogate and target to the same

\footnotetext{
${ }^{4}$ The requirement for federal agencies to consult regarding the effects of their actions on species listed as threatened or endangered under the ESA is set out in Section 7 of the Act. The duty to reinitiate consultation is described in regulations that implement Section 7 of the ESA (FWS and NMFS 2011).
}

environmental phenomena, link demographic responses to habitat extent and condition, and clearly describe the uncertainties that accompany the relationship between the status and trends of the surrogate and those of the target under common circumstances.

By addressing the concerns expressed herein in their final rule, the wildlife agencies can strengthen implementation of the ESA, which will ultimately contribute to achievement of its ultimate purpose of providing a means whereby the ecosystems upon which endangered species and threatened species depend may be conserved. Importantly, these changes are consistent with integration of the best available scientific information into implementation of the Act. That said, if the wildlife agencies fail to address the concerns we describe here, the rule may both be unlawful and harmful to the very species the Endangered Species Act was enacted to conserve.

Acknowledgments Support for this paper was provided by the Center for California Water Resources Policy and Management.

Open Access This article is distributed under the terms of the Creative Commons Attribution License which permits any use, distribution, and reproduction in any medium, provided the original author(s) and the source are credited.

\section{References}

Arizona Cattle Growers Assoc. v. U.S. Fish and Wildlife Service 200173 F.3d 1229 (9th Cir. 2001)

Austin MP, Nicholls AO, Margules CR (1990) Measurement of the realized qualitative niche: environmental niches of five Eucalyptus species. Ecol Monogr 60:161-177

Banks JE, Ackleh AS, Stark JD (2010) The use of surrogate species in risk assessment: using life history data to safeguard against false negatives. Risk Anal 30:175-182

Caro T (2010) Conservation by proxy. Island, Washington, D.C.

Caro TM, O'Doherty G (1999) On the use of surrogate species in conservation biology. Conserv Biol 13:805-814

Caro T, Eadie J, Sih A (2005) Use of substitute species in conservation biology. Conserv Biol 19:1821-1826

Center for Biological Diversity v. Bureau of Land Management 2006422 F. Supp. 2d 1115 (N.D. Cal. 2006)

Center for Biological Diversity v. National Marine Fisheries Service 2013 U.S. Dist. LEXIS 148920 (D.P.R. Sept. 30, 2013)

Cushman SA, McKelvey KS (2009) Data on distribution and abundance: monitoring for research and management. In: Cushman SA, McKelvey KS (eds) Spatial complexity, informatics, and wildlife conservation. Springer, New York, pp 111-129

Cushman SA, McKelvey KS, Noon BR, McGarigal K (2010) Use of abundance of one species as a surrogate for abundance of others. Conserv Biol 24:830-840

Dickson BG, Fleishman E, Dobkin DS, Hurteau SR (2009) Relationship between avifaunal occupancy and riparian vegetation in the central Great Basin (Nevada, U.S.A.). Restoration Ecology 17:722-730

Endangered Species Act (1973, as amended) United States Code, tit. 16, Sec. 1531-1544

Feyrer F, Nobriga M, Sommer T (2007) Multi-decadal trends for three declining fish species: habitat patterns and mechanisms in the San Francisco estuary. Can J Fish Aquat Sci 64:723-734 
Feyrer F, Newman K, Nobriga M, Sommer T (2008) Modeling the effects of water management actions on suitable habitat and abundance of a critically imperiled estuarine fish (delta smelt Hypomesus transpacificus). Manuscript in preparation

Fish and Wildlife Service (FWS), National Marine Fisheries Service (NMFS) (2013) Incidental take statements. Proposed Rule, Federal Register 78:54,437-54,442

Fish and Wildlife Service (2008) Biological opinion on the proposed coordinated operations of the Central Valley Project and State Water Project. Available from http://www.fws.gov/sfbaydelta/documents/ SWP-CVP OPs_BO_12-15 final_OCR.pdf

Fish and Wildlife Service (2012) 12-month finding on a petition to list the San Francisco Bay-Delta Population of the longfin smelt as endangered or threatened. Available from http://www.fws.gov/sfbaydelta/ documents/longfin_smelt_12-month_finding_3-29-2012.pdf

Fish and Wildlife Service (FWS), National Marine Fisheries Service (NMFS) (2011) Interagency cooperation-Endangered Species Act of 1973, as Amended, Code of Federal Regulations vol. 50 , pt. 402

Fleishman E, Murphy DD (2009) A realistic assessment of the indicator potential of butterflies and other charismatic taxonomic groups. Conserv Biol 23:1109-1116

Gaston KJ (1994) Rarity. Springer, New York

Government Accountability Office (2009) Endangered Species Act: The U.S. Fish and Wildlife Service has incomplete information about effects on listed species from Section 7 Consultations. Available from http://www.gao.gov/new.items/d09550.pdf

Hardin G (1960) The competitive exclusion principle. Science 131:12921297

Hutchinson GE (1961) The paradox of the plankton. Am Nat 95:137-145

Kimmerer WJ (2008) Losses of Sacramento River Chinook salmon and delta smelt to entrainment in water diversions in the Sacramento-San Joaquin Delta. San Francisco Estuary and Watershed Science 6(2): $1-27$

Lambeck RJ (1997) Focal species: a multi-species umbrella for nature conservation. Conserv Biol 11:849-856

Landres PB (1992) Ecological indicators: panacea or liability? In: McKenzie DH, Hyatt DE, McDonald VJ (eds) Ecological indicators, vol 2. Elsevier Applied Science, London, pp 1295-1318
Landres PB, Verner J, Thomas JW (1988) Ecological uses of vertebrate indicator species: a critique. Conserv Biol 2:316-328

Launer AE, Murphy DD (1994) Umbrella species and the conservation of habitat fragments: a case of a threatened butterfly and a vanishing grassland ecosystem. Biol Conserv 69:145-153

Lindenmayer DB, Manning AD, Smith PL, Possingham HP, Fischer J, Oliver I, McCarthy MA (2002) The focal-species approach and landscape restoration: a critique. Conserv Biol $16: 338-345$

Miccosukee Tribe of Indians of Florida v. U.S. 2009, 566 F.3d 1257 (11th Cir. 2009)

Murphy DD, Weiland PS, Cummins KW (2011) A critical assessment of the use of surrogate species in conservation planning in the Sacramento-San Joaquin Delta, California (U.S.A.). Conserv Biol $25: 873-878$

National Marine Fisheries Service (2009) Biological and conference opinion on the long-term operations of the Central Valley Project and State Water Project. Available from nrm.dfg.ca.gov/ FileHandler.ashx?DocumentID $=21473$

Oregon Natural Resources Council v. Allen 2007476 F.3d 1031 (9th Cir. 2007)

Rabinowitz D (1981) The seven forms of rarity. In: Synge H (ed) The biological aspects of rare plant conservation, pp. 205-217

Rose KA, Kimmerer WJ, Edwards KP, Bennett WA (2013a) Individualbased modeling of delta smelt population dynamics in the upper San Francisco estuary: I. Model description and baseline results. Trans Am Fish Soc 142:1238-1259

Rose KA, Kimmerer WJ, Edwards KP, Bennett WA (2013b) Alternative baselines and good versus bad years. Trans Am Fish Soc 142:1260 1272

Rosenfield JA, Baxter RD (2007) Population dynamics and distribution patterns of longfin smelt in the San Francisco estuary. Trans Am Fish Soc 136:1577-1592

Rowland MM, Wisdom MJ, Suring LH, Meinke CW (2006) Greater Sage Grouse as an umbrella species for sagebrush-associated vertebrates. Biol Conserv 129:323-339

Wenger SJ (2008) Use of surrogates to predict the stressor response of imperiled species. Conserv Biol 22:1564-1571 